Article

\title{
Regional Manufacturing Industry Demand Forecasting: A Deep Learning Approach
}

\author{
Zixin Dou ${ }^{1}\left(\mathbb{D}\right.$, Yanming Sun ${ }^{1,2, *}$, Yuan Zhang ${ }^{1,3}$, Tao Wang ${ }^{4}\left(\mathbb{D}\right.$, Chuliang $W_{u^{5}}$ and Shiqi Fan $^{6}(\mathbb{D}$ \\ 1 School of Management, Guangzhou University, Guangzhou 510000, China; 1111965001@e.gzhu.edu.cn (Z.D.); \\ 201620567@gzcc.edu.cn (Y.Z.) \\ 2 Research Center for High Quality Development of Modern Industry, Guangzhou University, \\ Guangzhou 510000, China \\ 3 School of Management, Guizhou University of Commerce, Guiyang 550014, China \\ 4 Department of Building Surveying, Faculty of Built Environment, University of Malaya, \\ Kuala Lumpur 50603, Malaysia; 17221416@siswa.um.edu.my \\ 5 School of Mathematics and Information Science, Guangzhou University, Guangzhou 510000, China; \\ fnlight0212@gmail.com \\ 6 Department of Engineering, The University of Hong Kong, Hong Kong 999077, China; \\ fsq247@connect.hku.hk \\ * Correspondence: sunyanming@gzhu.edu.cn
}

Citation: Dou, Z.; Sun, Y.; Zhang, Y.; Wang, T.; Wu, C.; Fan, S. Regional Manufacturing Industry Demand Forecasting: A Deep Learning Approach. Appl. Sci. 2021, 11, 6199. https://doi.org/10.3390/app11136199

Academic Editor: Barbara Strug

Received: 6 June 2021

Accepted: 1 July 2021

Published: 4 July 2021

Publisher's Note: MDPI stays neutral with regard to jurisdictional claims in published maps and institutional affiliations.

Copyright: (c) 2021 by the authors. Licensee MDPI, Basel, Switzerland. This article is an open access article distributed under the terms and conditions of the Creative Commons Attribution (CC BY) license (https:/ / creativecommons.org/licenses/by/ $4.0 /)$.

\begin{abstract}
With the rapid development of the manufacturing industry, demand forecasting has been important. In view of this, considering the influence of environmental complexity and diversity, this study aims to find a more accurate method to forecast manufacturing industry demand. On this basis, this paper utilizes a deep learning model for training and makes a comparative study through other models. The results show that: (1) the performance of deep learning is better than other methods; by comparing the results, the reliability of this study is verified. (2) Although the prediction based on the historical data of manufacturing demand alone is successful, the accuracy of the prediction results is significantly lower than when taking into account multiple factors. According to these results, we put forward the development strategy of the manufacturing industry in Guangdong. This will help promote the sustainable development of the manufacturing industry.
\end{abstract}

Keywords: manufacturing industry; demand forecasting; influence factor; deep learning

\section{Introduction}

Intelligent technology brings great opportunities and severe challenges to the highquality development of the manufacturing industry [1,2]. Demand forecasting is an important research field in many industries. The manufacturing industry generally tends to order sales. If the output is lower than the demand, the buyer chooses the manufacturer to meet the demand of their order, which means the chance of losing an order. On the other hand, if the output exceeds the actual demand, the inventory cost may increase. Therefore, a reasonable grasp of the manufacturing demand can help the government to plan from the perspective of macroeconomic regulation and control and can promote the manufacturing industry's avoidance of industrial surplus or shortage.

Improving the accuracy of manufacturing industry demand forecasting (MIDF) is important. However, the manufacturing industry is a field affected by many variables, including international relations [3], government policies [4], economic level [5], services industry [6], and technology level [7]. Demand forecasting is facing challenges. Therefore, this paper needs to build a prediction system to help screen variables.

In recent years, there have been many research methods of industrial demand forecasting. The first is the traditional classical regression method [8]. Later, with the development of technology, machine learning has been widely used in industrial demand forecasting, such as random forest (RF) [9], grey model (GM $(1,1))[10]$, support vector machine 
(SVM) [11], and neural network (NN) [12]. Particularly, SVM and neural networks are the most prominent. In terms of SVM, Meza et al. [13] used SVM to predict municipal solid waste and found that it was more robust. Shao et al. [14] used SVM to estimate the energy consumption of hotel buildings and found that the error of the results was small. In terms of NN, Thomas et al. [15] used a linear regression model to predict the demand for private housing. Law's [16] research found that although the traditional prediction methods can achieve good prediction results in the field of tourism demand, the NN prediction results are better. Enyiit et al. [17] found that the artificial neural network method is better than other methods. Tanizaki et al. [18] used NN to predict restaurant demand. However, the $\mathrm{NN}$ is better than traditional methods, but in terms of the correlation between predicted data and actual data, traditional methods are better than NN. This shows that NN is not sufficient to deal with the relationship between data in some aspects. In addition, few scholars apply deep learning to industrial demand forecasting.

To address these knowledge gaps: (1) considering the environmental complexity and diversity of the manufacturing, this paper constructs the MIDF system to improve the accuracy of MIDF. (2) In this context, the deep learning model is established to forecast the manufacturing industry demand with the minimum error rate. Therefore, this study enables us to reveal the influence of variables and how the deep learning model works on these variables.

The rest of this paper is as follows (as shown in Figure 1): Section 2 summarizes the literature reviews. In Section 3, we introduce the research framework, namely, the prediction system, research model, and evaluation methods. The next section is an experiment, including alternative models and demand forecasting. Section 5 discusses theoretical and practical implications. Finally, the conclusion is presented.

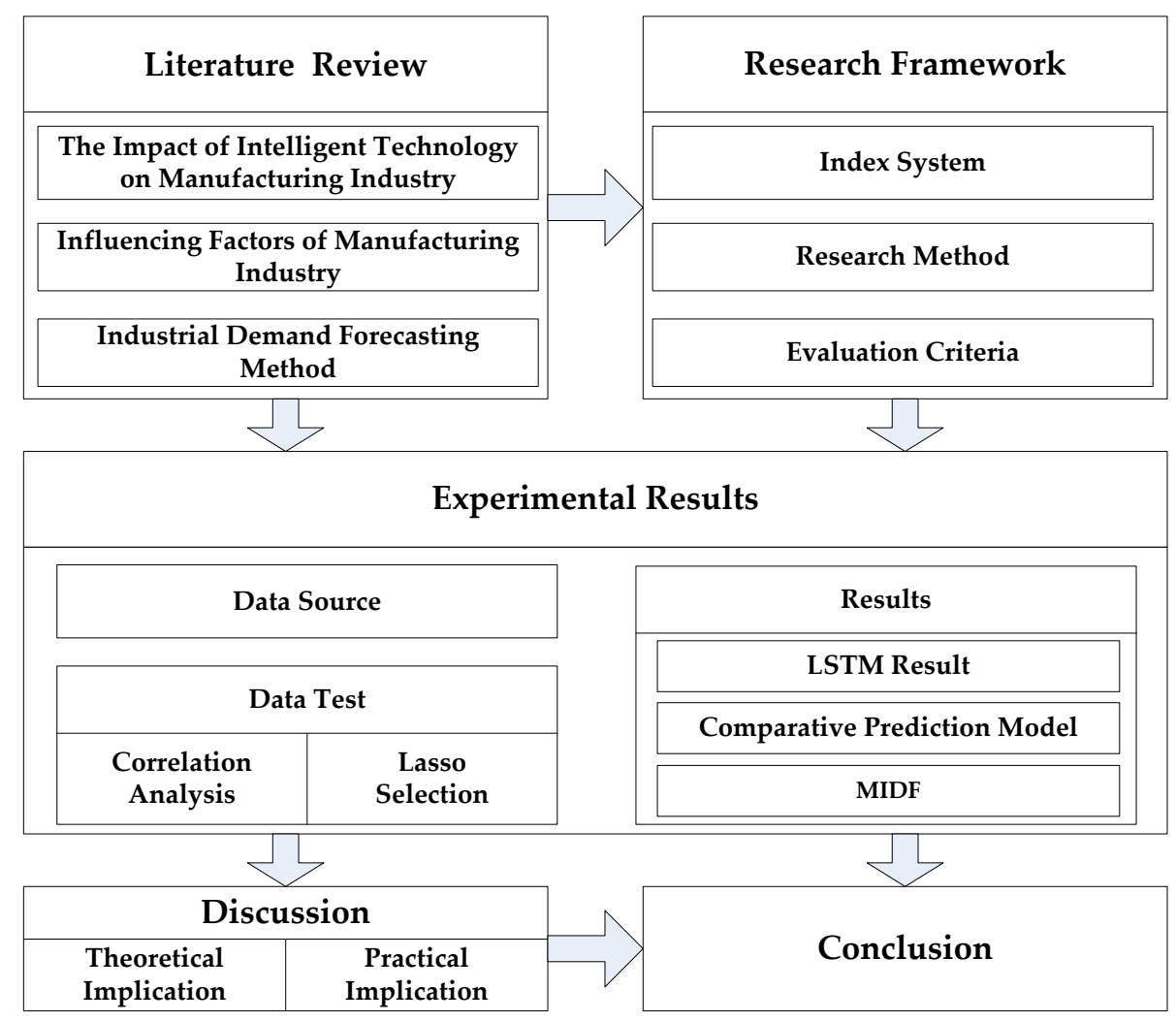

Figure 1. The graphical framework. 


\section{Literature Review}

\subsection{The Impact of Intelligent Technology on the Manufacturing Industry}

Liu et al. [19] discussed the impact of intelligent technology on the manufacturing industry. In other words, with the rapid development of intelligent technology, the highquality development of the manufacturing industry can be promoted.

The research on intelligent technology driving the manufacturing industry development is in the rising stage. In terms of robotics, Acemoglu et al. [20] found that the value-added and productivity of enterprises using robots increased significantly. In addition, the intelligent technology system has also improved the manufacturing industry. For example, Yu et al. [21] found that a network physical manufacturing system (CPS) can help the manufacturing industry to adapt to the new market demand. Romero-Silva et al. [22] analyzed the correlation of CPS and found it can help enterprises to improve their advantage. On the other hand, intelligent technology promotes the development of the latest manufacturing modes, such as ecological marketing manufacturing mode [23], data-driven manufacturing mode [24], and customer service manufacturing mode [25].

The development of intelligent technology not only promotes the high-quality development of the manufacturing industry, but it also extends its development mode. Given this, the impact of intelligent technology will be considered when constructing the MIDF index system.

\subsection{Influencing Factors of the Manufacturing Industry}

Many scholars have studied the factors affecting the manufacturing industry in different situations. In terms of foreign direct investment (FCI), Raluca et al. [26] found that FCI has become one of the most important factors in promoting the development of the manufacturing industry in Romania. Fernandes et al. [27] found that FCI promoted innovation activities in the manufacturing industry. Huang et al. [28] found that FCI strategy significantly enhanced productivity growth. In terms of government, Liu et al. found that fiscal subsidies have a positive effect on the economic performance and sustainable management of manufacturing enterprises [29]. Zhao et al. [30] found that fiscal subsidies to manufacturing enterprises can improve the market competitiveness of their products. In terms of economics, Szirmai et al. [31] found that the manufacturing industry has a moderately positive influence on economic growth. Gabriel et al. [32] found that manufacturing can be the "growth engine" of developing countries. In terms of services, Jiang et al. [33] found that developing countries are more engaged in low value-added services, such as warehousing. Liu et al. [34] discussed the impact of the service industry on the export performance of the manufacturing industry. It is found that financial and business services have enhanced the comparative advantage of the manufacturing sector. In terms of technology, Dou et al. [35] found that intellectual property rights can promote the competitiveness of the manufacturing industry in developed countries. Dou et al. [36] found that technology has a radiation effect on the regional urban manufacturing industry, which can promote its sustainable development. $\mathrm{Xu}$ et al. [37] found that intellectual property has a positive influence on the Korean manufacturing industry. Additionally, it is worth noting that scholars mostly use the number of patent applications [38,39], the sales volume of new products [40], and R\&D [41,42] as the representatives of the technical level.

The above research results have a good reference value for the construction of the GD's MIDF index system. These can more truly reflect the scale of manufacturing industry demand, thus expanding the index system of manufacturing industry demand.

\subsection{Industrial Demand Forecasting Method}

Industrial demand forecasting is mainly based on quantitative methods, including regression models, GM $(1,1), \mathrm{SVM}, \mathrm{NN}$, and so on. In terms of the regression model, Maao et al. [8] forecasted industrial energy demand based on the multiple linear regression method. Huang et al. [43] used the multiple regression model to forecast tea demand. Yu et al. [44] used the regression model to predict the demand for films. In terms of the 
GM $(1,1)$ model, Yan et al. [10] used GM $(1,1)$ to forecast logistics demand. Hu et al. [45] used GM $(1,1)$ to forecast the demand for magnesium products. In terms of the RF model, Everingham et al. [9] established an RF model to predict the demand for agricultural products. Sathishkumar et al. [46] used RF to effectively forecast bicycle rental demand. In terms of the SVM model, Yan et al. [11] used SVM to forecast freight volume demand. Jie et al. [47] used SVM to forecast the generation of photovoltaic power generation systems. Fan et al. [48] used SVM to forecast the logistics demand. Compared with the above methods, the NN has the abilities of nonlinear mapping and fault tolerance [49]. In terms of the NN model, Güven et al. [12] studied the retail clothing industry and established a NN for sales forecasting. Yin et al. [50] used a NN to predict the urban water-energy demand. Huang et al. [51] used a NN to forecast the movie box office demand.

In summary, this paper finds that the literature on MIDF is relatively lacking, but the existing research results can provide a wealth of literature for the manufacturing industry demand forecasting model. In other words, existing research can provide a reference for this paper to choose a prediction model. In addition, although a NN more easily fits complex nonlinear relationships, in essence, the accuracy of it will be affected by many factors, such as nonlinear characteristic factors and gradient disappearances. Therefore, the Long Short-Term Memory (LSTM) network, proposed by Hochreiter [52], is suitable for manufacturing industry demand forecasting. Meanwhile, to verify the accuracy of the LSTM network, a variety of prediction models are used as the comparison model.

\section{Research Framework}

The purpose of this study is the MIDF of GD. Based on the literature review, the research process is shown in Figure 2. The research framework includes the following six steps:

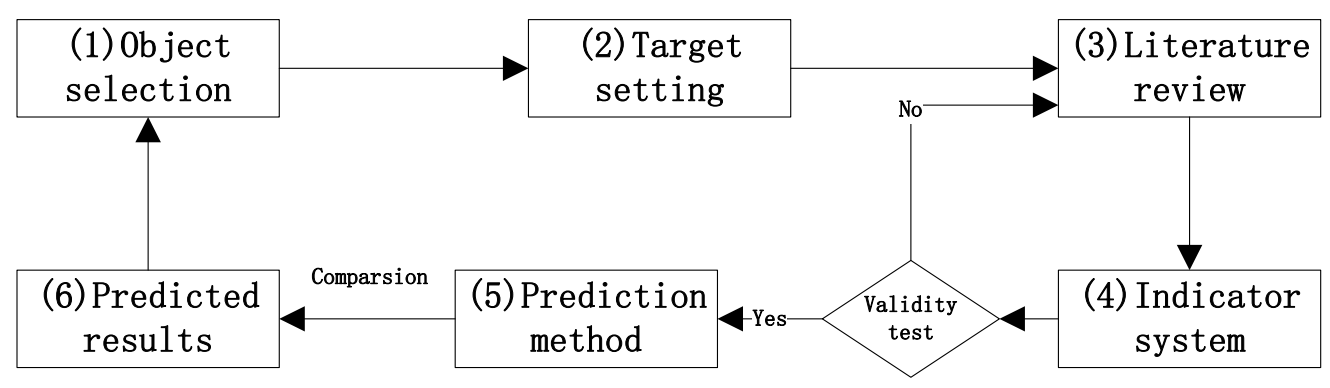

Figure 2. The research framework.

Step 1-Research objective selection: the manufacturing industry demand of GD.

Step 2-Target setting: forecasting manufacturing industry demand for the next three years. Step 3-Literature review: the preliminary screening of indexes and data collection.

Step 4-construction of an index system. Through correlation analysis and lasso characteristic analysis, we can judge whether these indicators are reasonable.

Step 5-select the prediction method. Five methods are used to forecast the demand of the manufacturing industry.

Step 6-predicted results: choose the method of minimum error to forecast the manufacturing industry demand of GD for the next three years.

\subsection{Index System}

The manufacturing environment is a well-defined whole. In the index system of MIDF, a single index can reflect one side of manufacturing industry demand, and the synthesis of the index can reflect the overall situation of manufacturing industry demand. Therefore, this paper constructs the index system from the perspective of the internal environment (technology) and external environment (multidimensional), as shown in Figure 3 and Table 1. 


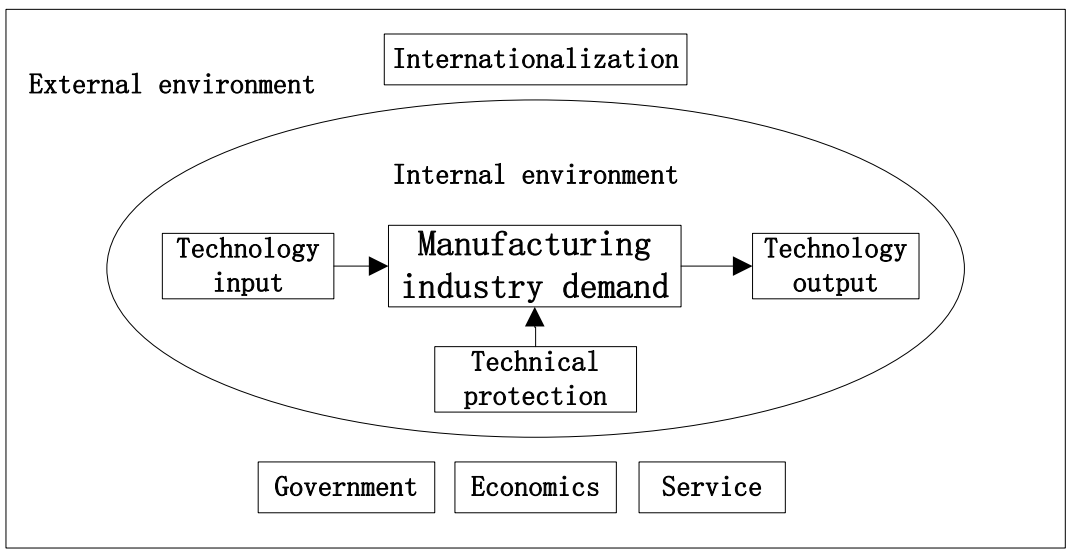

Figure 3. The index system for MIDF.

Table 1. The index system for MIDF.

\begin{tabular}{ccc}
\hline Research Target & Influence Variables & Variable Explanation \\
\hline & FCI $(\mathrm{X} 1)[26-28]$ & International co-operation \\
& General Public Budget Expenditure for & Government subsidies \\
Science and Technology $(\mathrm{X} 2)[29,30]$ & Economic development \\
GDP $(\mathrm{X} 3)[31,32]$ & Service level \\
& Tertiary Industry $(\mathrm{X} 4)[33,34]$ & Technical protection \\
Number of Patent Applications & Granted $(\mathrm{X} 5)[38,39]$ & Technology input \\
& Internal Expenditure on R\&D $(\mathrm{X6})[40]$ & Technology output \\
\hline
\end{tabular}

\subsection{Research Method}

LSTM was then applied to other fields [53,54], which proved that it has strong universality. By introducing a "gating unit", it can solve the long-term dependence problem, including forget gate, input gate, and output gate. In addition, memory cells also play an important role in LSTM. The network structure is shown in Figure 4.

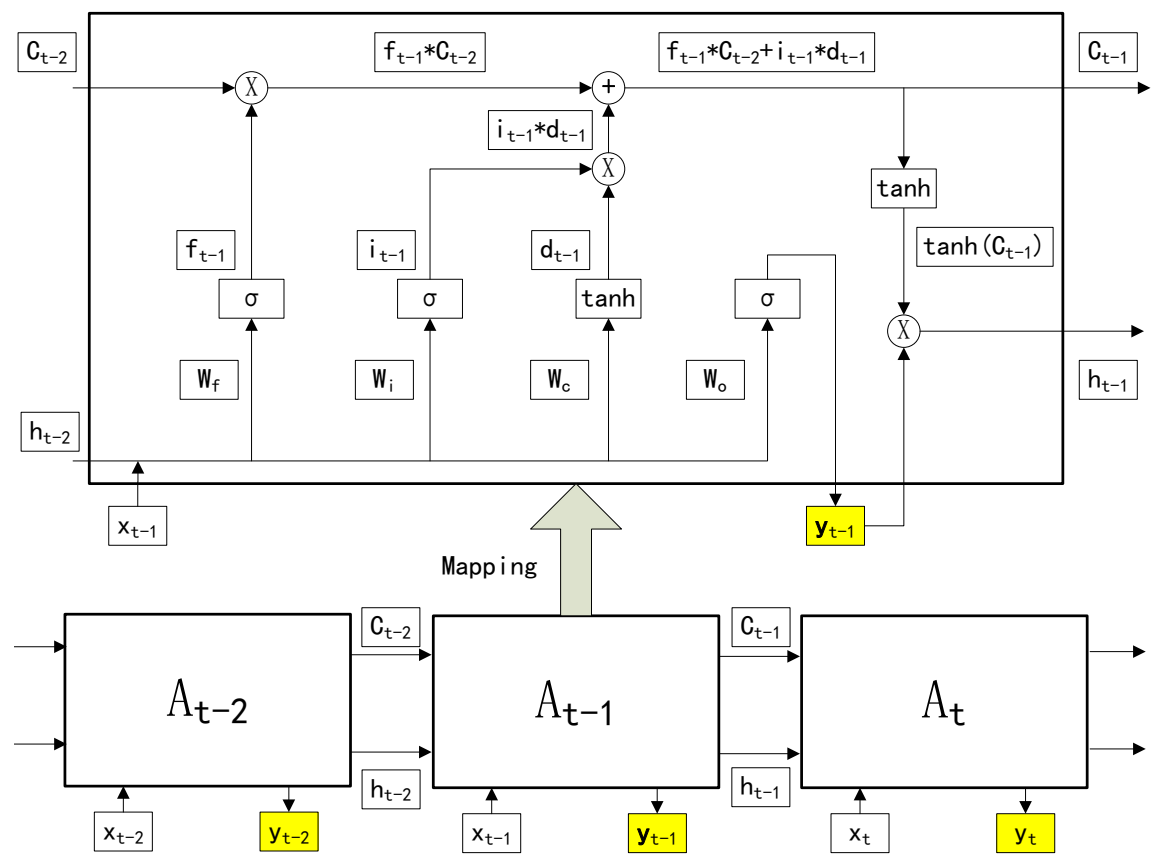

Figure 4. The network structure of LSTM. 
For the same LSTM, its "At-i structure" is fixed and shares the same parameters. The upper flow chart in Figure 3 is the specific process of "At-i structure" mapping. The steps are as follows:

Step 1-Forgetting gate: it can judge whether historical information needs to be forgotten or not. The formula is as follows:

$$
f_{t-1}=\sigma\left(W_{f} *\left[h_{t-2}, x_{t-1}\right]+b_{f}\right)
$$

where $\sigma$ is the sigmoid function, $W_{f}$ is the weight matrix of the variable, $h_{t-2}$ is the hidden layer output at $t-2, x_{t-1}$ is the input at $t-1$, and $b_{f}$ is the deviation vector.

Step 2-Input gate: the input gate determines what information will be retained in the memory unit. The formulas are as follows:

$$
\begin{aligned}
& i_{t-1}=\sigma\left(W_{i} *\left[h_{t-2}, x_{t-1}\right]+b_{i}\right) \\
& d_{t-1}=\sigma\left(W_{c} *\left[h_{t-2}, x_{t-1}\right]+b_{c}\right) \\
& C_{t-1}=f_{t-1} * C_{t-2}+i_{t-1} * d_{t-1}
\end{aligned}
$$

where $C_{t-2}$ and $C_{t-1}$ are the values of $t-2$ and $t-1$ time memory units, respectively, and $i_{t-1} * d_{t-1}$ is the updated value of the memory unit.

Step 3-Output gate: it consists of two parts. First, the output information is determined by $h_{t-2}, x_{t-1}$ and the activation function. Then, the tanh activation function acts on the memory unit $C_{t-1}$ and multiplies it to get the output $h_{t-1}$. The formulas are as follows:

$$
\begin{gathered}
y_{t-1}=\sigma\left(W_{y} *\left[h_{t-2}, x_{t-1}\right]+b_{y}\right) \\
h_{t-1}=y_{t-1} * \tanh \left(C_{t-1}\right)
\end{gathered}
$$

By the above iteration, with the $x_{t}$ input, the model can predict the future value $y_{t}$.

Due to the ingenious setting of the forget gate, input gate, output gate, and memory unit, the LSTM network can retain useful information.

\subsection{Evaluation Criteria}

To verify the accuracy and effectiveness of the model, most scholars use a variety of evaluation criteria $[55,56]$. Therefore, the mean absolute error (MAE), root-mean-square error (RMSE), and mean absolute percentage error (MAPE) are used to evaluate the accuracy. The formulas are as follows:

$$
\begin{aligned}
\text { MAPE } & =\frac{1}{\text { total }} \sum_{i=1}^{\text {Total }} \frac{\left|Y_{i}-Y^{*}{ }_{i}\right|}{Y_{i}} \\
\text { MAE } & =\frac{1}{\text { total }} \sum_{i=1}^{\text {Total }}\left|Y_{i}-Y^{*}{ }_{i}\right| \\
\text { RMSE } & =\sqrt{\frac{1}{\text { total }} \sum_{i=1}^{\text {Total }}\left|Y_{i}-Y^{*}{ }_{i}\right|^{2}}
\end{aligned}
$$

where total is the total amount of test data, and $Y_{i}$ and $Y^{*}{ }_{i}$ represent the predict and actual value, respectively. All accuracy results are averages of 10 independent runs.

\section{Experimental Results}

\subsection{Data Source}

With the reform and opening, the manufacturing industry in GD has become a national strategic industrial base, and advanced manufacturing is the leading industry with a large scale and a complete system. From 2004 to 2019, its total industrial value increased from 
2955.492 billion to $16,412,172$ billion yuan, showing a relatively obvious development speed. Therefore, it is reasonable to choose GD as the research object.

In this paper, the total industrial value in the Statistical Yearbook of GD was selected to represent the demand of the manufacturing industry. Other indicators are from this statistical yearbook from 2005 to 2020 . However, considering the small amount of data, this paper uses the method of the mean value of adjacent points to expand the data set.

Finally, the data set of this paper is shown in Table 2. Among them, the whole year is the original data, and the data including months are the extended data.

Table 2. The GD's MIDF data sample.

\begin{tabular}{|c|c|c|c|c|c|c|c|c|}
\hline Year/Month & $\mathbf{Y}$ & X1 & $\mathrm{X} 2$ & X3 & $X 4$ & X5 & X6 & $\mathrm{X} 7$ \\
\hline 2004 & $29,554.92$ & 828.64 & 56.42 & $18,658.34$ & 8246.80 & 1941.00 & 147.56 & 3055.19 \\
\hline $2004 / 6$ & $32,748.83$ & 920.73 & 62.56 & $20,310.67$ & 8882.68 & 1908.50 & 163.98 & 3219.53 \\
\hline 2005 & $35,942.74$ & 1012.81 & 68.70 & $21,962.99$ & 9518.55 & 1876.00 & 180.39 & 3383.88 \\
\hline $2005 / 6$ & $40,308.75$ & 1084.79 & 74.19 & $23,962.12$ & $10,413.55$ & 2158.50 & 213.74 & 3800.21 \\
\hline 2006 & $44,674.75$ & 1156.76 & 79.67 & $25,961.24$ & $11,308.54$ & 2441.00 & 247.08 & 4216.53 \\
\hline $2006 / 6$ & $49,963.81$ & 1229.51 & 99.47 & $28,851.93$ & $12,682.55$ & 3077.50 & 291.72 & 4493.44 \\
\hline 2007 & $55,252.86$ & 1302.26 & 119.26 & $31,742.61$ & $14,056.56$ & 3714.00 & 336.37 & 4770.34 \\
\hline $2007 / 6$ & $60,338.74$ & 1316.72 & 125.89 & $34,223.39$ & $15,160.26$ & 5659.00 & 373.66 & 5936.91 \\
\hline 2008 & $65,424.61$ & 1331.17 & 132.52 & $36,704.16$ & $16,263.96$ & 7604.00 & 410.96 & 7103.48 \\
\hline $2008 / 6$ & $66,850.19$ & 1332.79 & 150.51 & $38,084.43$ & $17,171.50$ & 9479.50 & 481.67 & 7699.51 \\
\hline 2009 & $68,275.77$ & 1334.41 & 168.50 & $39,464.69$ & $18,079.03$ & $11,355.00$ & 552.37 & 8295.55 \\
\hline $2009 / 6$ & $77,050.21$ & 1352.99 & 191.47 & $42,704.66$ & $19,453.31$ & $12,523.00$ & 628.03 & $10,083.92$ \\
\hline 2010 & $85,824.64$ & 1371.57 & 214.44 & $45,944.62$ & $20,827.59$ & $13,691.00$ & 703.68 & $11,872.29$ \\
\hline $2010 / 6$ & $90,348.16$ & 1389.74 & 209.18 & $49,508.71$ & $22,593.07$ & $15,966.50$ & 801.56 & $13,127.28$ \\
\hline 2011 & $94,871.68$ & 1407.91 & 203.92 & $53,072.79$ & $24,358.54$ & $18,242.00$ & 899.44 & $14,382.27$ \\
\hline $2011 / 6$ & $95,236.89$ & 1447.23 & 225.32 & $55,040.27$ & $25,654.42$ & $20,197.50$ & 988.65 & $14,892.56$ \\
\hline 2012 & $95,602.09$ & 1486.54 & 246.71 & $57,007.74$ & $26,950.30$ & $22,153.00$ & 1077.86 & $15,402.85$ \\
\hline $2012 / 6$ & $102,637.58$ & 1515.94 & 295.83 & $59,755.58$ & $28,617.16$ & $21,118.50$ & 1157.67 & $16,708.29$ \\
\hline 2013 & $109,673.07$ & 1545.33 & 344.94 & $62,503.41$ & $30,284.02$ & $20,084.00$ & 1237.48 & $18,013.74$ \\
\hline $2013 / 6$ & $114,693.06$ & 1598.00 & 309.64 & $65,338.22$ & $31,743.99$ & $21,180.00$ & 1306.38 & $19,163.53$ \\
\hline 2014 & $119,713.04$ & 1650.66 & 274.33 & $68,173.03$ & $33,203.95$ & $22,276.00$ & 1375.29 & $20,313.32$ \\
\hline $2014 / 6$ & $122,181.10$ & 1662.28 & 421.94 & $71,452.74$ & $35,416.44$ & $27,876.50$ & 1447.92 & $21,477.91$ \\
\hline 2015 & $124,649.16$ & 1673.91 & 569.55 & $74,732.44$ & $37,628.92$ & $33,477.00$ & 1520.55 & $22,642.50$ \\
\hline $2015 / 6$ & $129,208.60$ & 1612.42 & 656.26 & $78,447.83$ & $40,396.21$ & $36,051.50$ & 1598.41 & $25,656.96$ \\
\hline 2016 & $133,768.04$ & 1550.92 & 742.97 & $82,163.22$ & $43,163.49$ & $38,626.00$ & 1676.27 & $28,671.41$ \\
\hline $2016 / 6$ & $134,745.23$ & 1548.77 & 783.43 & $86,905.98$ & $46,332.09$ & $42,183.00$ & 1770.65 & $31,767.22$ \\
\hline 2017 & $135,722.42$ & 1546.61 & 823.89 & $91,648.73$ & $49,500.68$ & $45,740.00$ & 1865.03 & $34,863.03$ \\
\hline $2017 / 6$ & $138,060.68$ & 1498.75 & 929.30 & $95,796.98$ & $52,105.53$ & $49,499.50$ & 1986.12 & $37,119.54$ \\
\hline 2018 & $140,398.93$ & 1450.88 & 1034.71 & $99,945.22$ & $54,710.37$ & $53,259.00$ & 2107.20 & $39,376.06$ \\
\hline $2018 / 6$ & $143,260.33$ & 1486.44 & 1101.75 & $103,808.15$ & $57,241.88$ & $56,500.50$ & 2211.03 & $41,173.06$ \\
\hline 2019 & $146,121.72$ & 1522.00 & 1168.79 & $107,671.07$ & $59,773.38$ & $59,742.00$ & 2314.86 & $42,970.06$ \\
\hline
\end{tabular}

For the original data, we used the shuffle function in the sklear.utils library to randomly sort these data. Then, the train_test_split function of the sklear.model_selection library in Python was used to split the data with the $80 / 20$ rule. Thus, the effect of randomly dividing the training set and the test set was achieved. Through many experiments, this can train the data completely.

\subsection{Data Test}

\subsubsection{Correlation Analysis}

According to the literature, manufacturing industry demand is related to seven indicator variables. From Figure 5, we can see that the order of correlation between these seven factors is $\mathrm{X} 3>\mathrm{X} 6>\mathrm{X} 4>\mathrm{X} 7>\mathrm{X} 5>\mathrm{X} 1>\mathrm{X} 2$. As the correlation values of the seven indicators are all greater than 0.6 , it shows that these indicators apply to the prediction of manufacturing demand. 


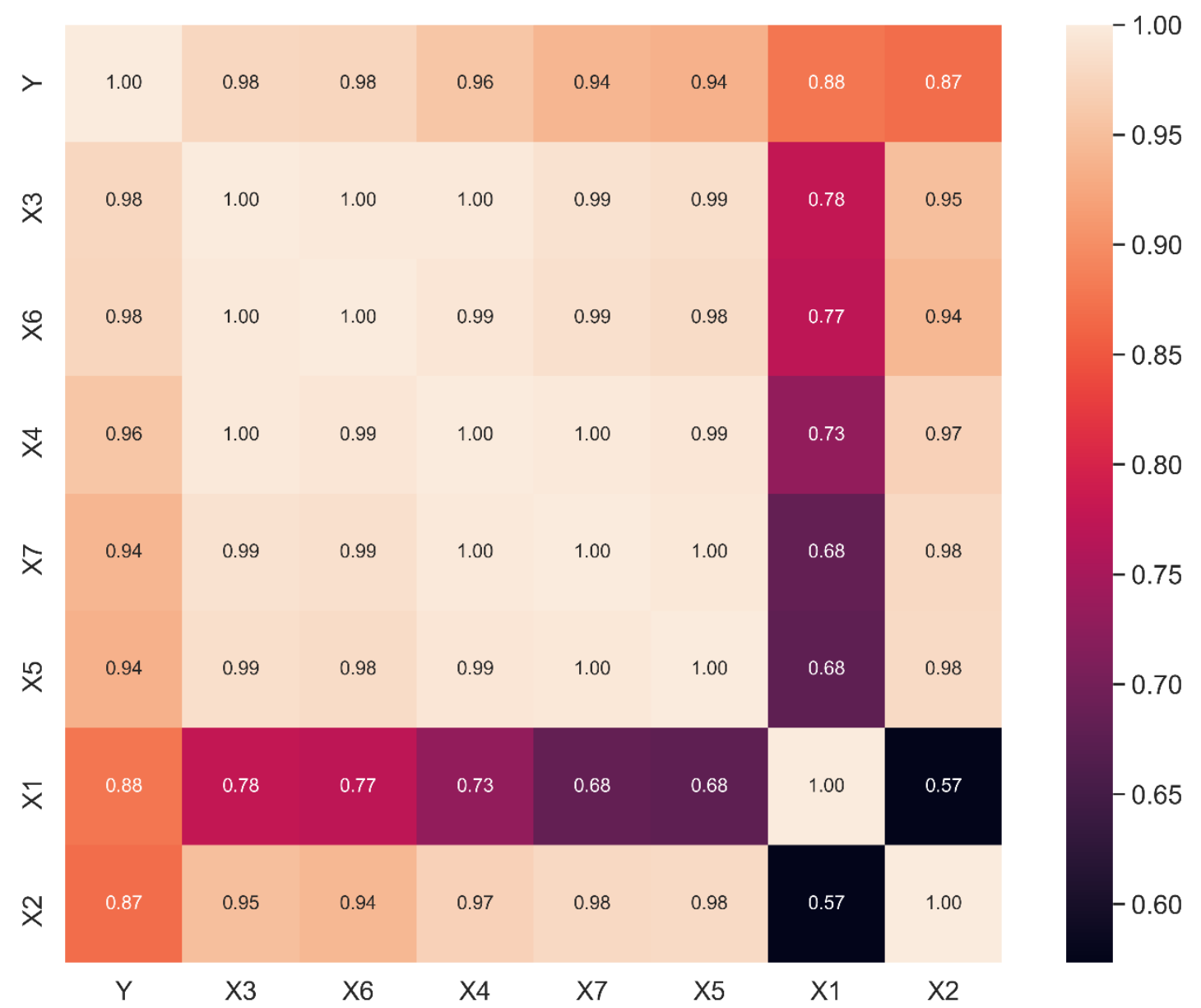

Figure 5. The index correlation graph.

\subsubsection{Lasso Selection}

In the exploratory analysis of data, there are too many features introduced, so it is necessary to further screen the original features and only retain the important features. The Lasso method can compress the regression coefficient of unimportant indexes to zero, to achieve the purpose of index selection. After the regression of Lasso, the values of each index are shown in Table 3.

Table 3. Indexes of the Lasso regression coefficient.

\begin{tabular}{cccccccc}
\hline & $\mathbf{X 1}$ & $\mathbf{X 2}$ & $\mathbf{X 3}$ & $\mathbf{X} 4$ & $\mathbf{X 5}$ & $\mathbf{X 6}$ & $\mathbf{X 7}$ \\
\hline $\begin{array}{c}\text { The } \\
\text { coefficient }\end{array}$ & 43.68 & -13.51 & 1.24 & -2.16 & 0.19 & 25.57 & 1.10 \\
\hline The state & True & True & True & True & True & True & True \\
\hline
\end{tabular}

The results show that the values of each index are not zero. Therefore, the above indicators are the key factors affecting the manufacturing industry demand, and these characteristics can be used for further research.

\subsection{Results}

\subsubsection{LSTM Result}

Python is used to train the LSTM network. The training status and regression results are shown in Figures 6 and 7, respectively. The results show that LSTM training converged 
very fast, and there was no fitting phenomenon. At the same time, the prediction was accurate, which is consistent with the basic historical data.

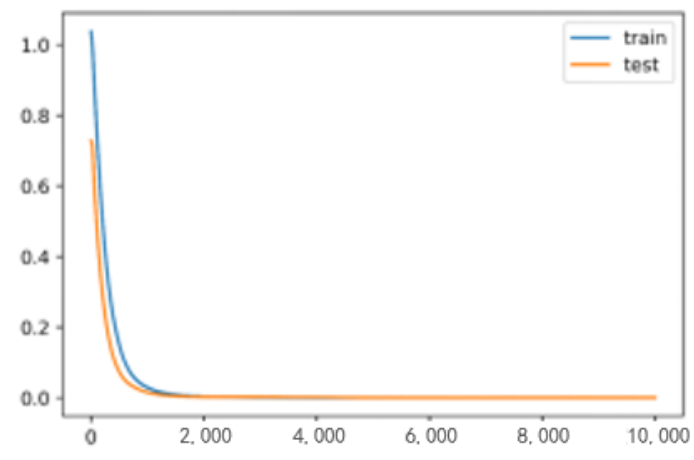

Figure 6. The LSTM training result.

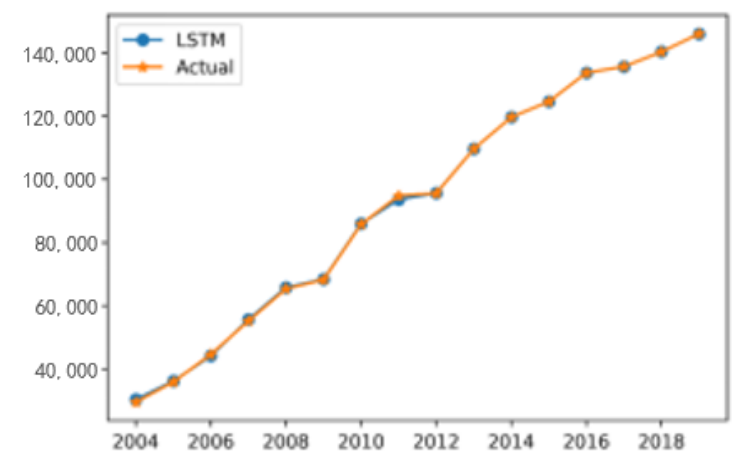

Figure 7. The LSTM prediction results.

\subsubsection{Comparative Prediction Model}

To verify the accuracy of LSTM, this paper compared it with four models, namely, SVM, BP, RF, and AR. The input indexes of all models were consistent. Because the data units of each index are different, to get more accurate prediction results, the original data of each index were normalized and mapped to [0,1] [57].

\subsubsection{Manufacturing Industry Demand Forecasting}

In this step, first of all, we need to predict the auto-regressive time of each $X i$ factor. Then, based on the forecast factors, LSTM is used to forecast the manufacturing demand in the next three years.

We used LSTM, BP, and GM models to predict the future values of these factors through historical data. It is worth noting that the reason for choosing these three models is that LSTM and BP had excellent results in the previous comparative experiments. The GM $(1,1)$ model is the classic model in the field of auto-regression.

By comparison, although the prediction based on the historical data of $Y$ was successful, it did not seem to give a more accurate result. Specifically, the above three methods only used the historical data of $\mathrm{Y}$ for auto-regressive prediction, which is significantly lower than the prediction results of LSTM considering multiple factors in Table 4. Therefore, to make an accurate forecast, we should consider the factors that affect the demand.

Table 4. Average results of different prediction models.

\begin{tabular}{cccccc}
\hline & LSTM & SVM & BP & AR & RF \\
\hline MAE & 463.4339183 & 2891.278648 & 1074.917976 & 2019.226016 & 1397.206419 \\
RMSE & 874.8308509 & 3840.997444 & 1446.326249 & 2783.584018 & 2125.591786 \\
MAPE & $0.63 \%$ & $3.59 \%$ & $1.28 \%$ & $3.12 \%$ & $2.49 \%$ \\
\hline
\end{tabular}


From Table 5, both LSTM and BP had excellent performance in auto-regressive prediction. Because the structure of the BP network was simpler, its training speed was faster than LSTM (as shown in Figures 8 and 9). Therefore, it is more reasonable to choose BP to predict the future value of each factor.

Using LSTM, combined with the predicted values of each factor (see Table 6), this paper predicts the manufacturing demand of GD from 2020 to 2022. In Table 7 and Figure 10, the predicted results were 14,708.04 billion yuan, 14,878.35 billion yuan, and 1497.72 billion yuan, respectively. According to the forecast data, from 2004 to 2022, the demand of GD's manufacturing industry will increase from 2955.492 billion to 14,977.24 billion yuan, with an average annual growth of $8.92 \%$.

Table 5. Accuracy of factor prediction.

\begin{tabular}{|c|c|c|c|c|}
\hline & & LSTM & BP & GM(1,1) \\
\hline \multirow{3}{*}{$\mathrm{X} 1$} & MAE & 24.40906 & 23.10708 & 85.94395 \\
\hline & RMSE & 29.53632 & 30.3987 & 105.9244 \\
\hline & MAPE & $1.90 \%$ & $1.54 \%$ & $6.16 \%$ \\
\hline \multirow{3}{*}{$\mathrm{X} 2$} & MAE & 21.92619 & 19.14836 & 43.33882 \\
\hline & RMSE & 34.78503 & 31.27112 & 59.63684 \\
\hline & MAPE & $6.84 \%$ & $6.07 \%$ & $13.52 \%$ \\
\hline \multirow{3}{*}{$\mathrm{X} 3$} & MAE & 417.0695 & 307.9188 & 1809.08 \\
\hline & RMSE & 605.0364 & 384.5287 & 2440.184 \\
\hline & MAPE & $0.82 \%$ & $0.69 \%$ & $4.66 \%$ \\
\hline \multirow{3}{*}{$X 4$} & MAE & 197.5453 & 148.132 & 716.5678 \\
\hline & RMSE & 239.7368 & 170.3009 & 991.3312 \\
\hline & MAPE & $0.83 \%$ & $0.66 \%$ & $3.61 \%$ \\
\hline \multirow{3}{*}{ X5 } & MAE & 825.8111 & 657.8572 & 4130.789 \\
\hline & RMSE & 1257.428 & 981.4491 & 5145.899 \\
\hline & MAPE & $7.33 \%$ & $6.05 \%$ & $46.90 \%$ \\
\hline \multirow{3}{*}{ X6 } & MAE & 5.059089 & 5.213758 & 131.1709 \\
\hline & RMSE & 6.703232 & 6.394745 & 159.7326 \\
\hline & MAPE & $0.97 \%$ & $0.93 \%$ & $24.89 \%$ \\
\hline \multirow{3}{*}{$X 7$} & MAE & 393.3796 & 203.6164 & 1507.022 \\
\hline & RMSE & 493.4832 & 289.1982 & 1955.195 \\
\hline & MAPE & $3.37 \%$ & $2.25 \%$ & $14.87 \%$ \\
\hline \multirow{3}{*}{$\mathrm{Y}$} & MAE & 4852.551 & 1443.969 & 7749.021 \\
\hline & RMSE & 6092.578 & 1993.786 & 9211.345 \\
\hline & MAPE & $5.46 \%$ & $1.56 \%$ & $10.31 \%$ \\
\hline
\end{tabular}

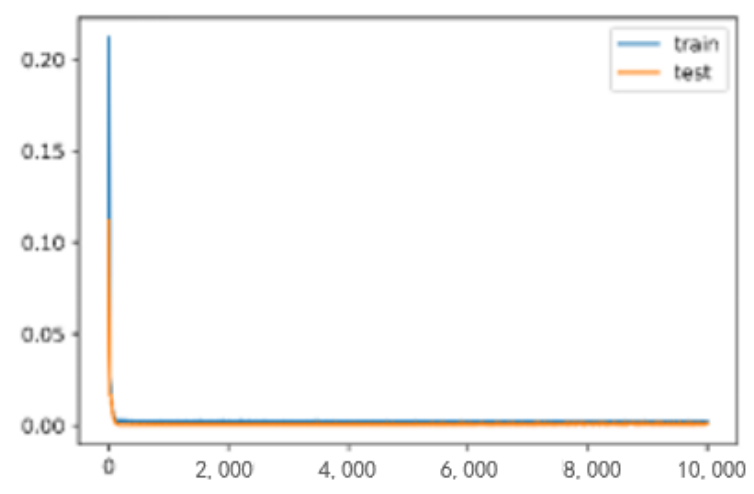

Figure 8. The auto-regressive training result of BP. 


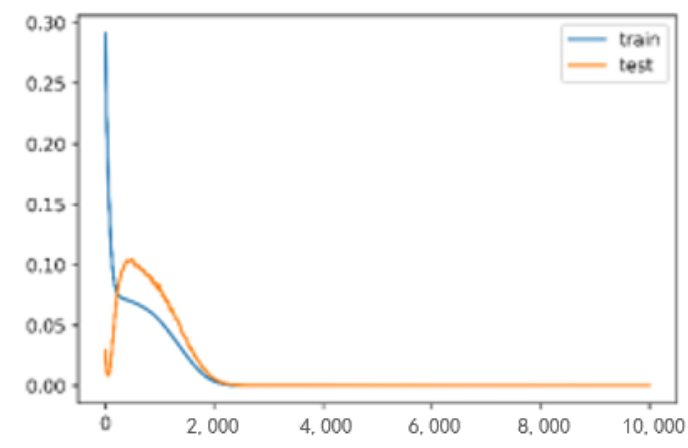

Figure 9. The auto-regressive training result of LSTM.

Table 6. Factor forecast for the next three years.

\begin{tabular}{cccc}
\hline Year & $\mathbf{2 0 2 0}$ & $\mathbf{2 0 2 1}$ & $\mathbf{2 0 2 2}$ \\
\hline X1 & 1558.81 & 1581.46 & 1603.743652 \\
X2 & 1290.37 & 1380.12 & 1438.61 \\
X3 & $114,712.38$ & $121,186.86$ & $126,723.83$ \\
X4 & $64,732.88$ & $69,585.25$ & $74,398.74$ \\
X5 & $65,494.22$ & $70,856.7$ & $79,074.36$ \\
X6 & 2480.69 & 2619.76 & 2752.09 \\
X7 & $45,951.31$ & $48,622.86$ & $51,048.66$ \\
\hline
\end{tabular}

Table 7. The GD's MIDF for the next three years.

\begin{tabular}{cccc}
\hline & $\mathbf{2 0 2 0}$ & $\mathbf{2 0 2 1}$ & $\mathbf{2 0 2 2}$ \\
\hline $\mathrm{Y}$ & $147,080.37$ & $148,783.48$ & $149,772.4$ \\
\hline
\end{tabular}

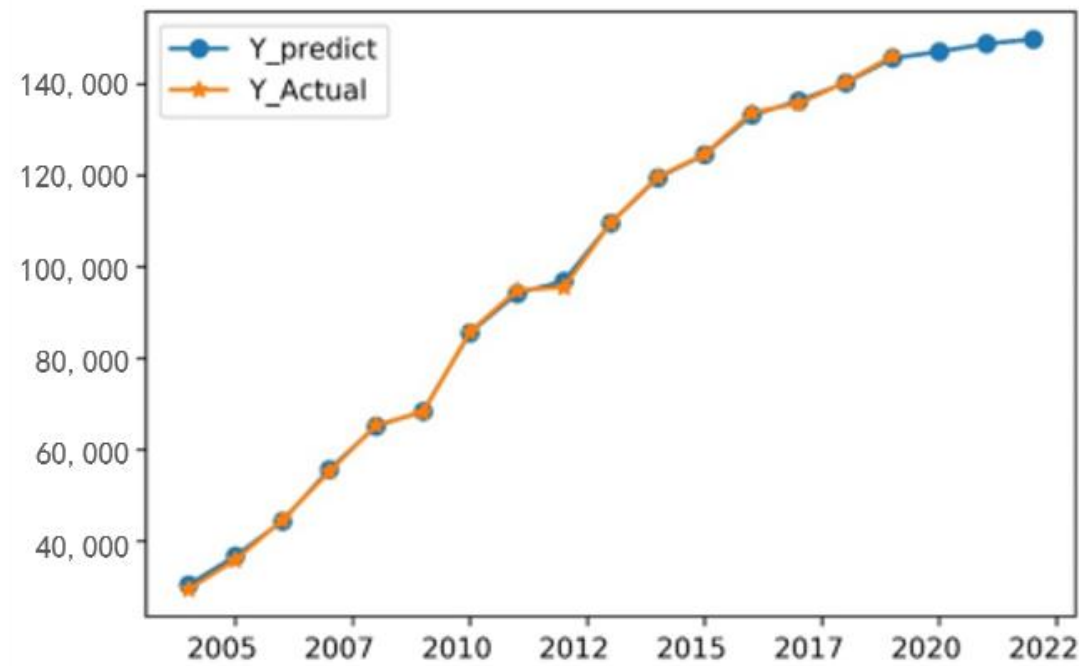

Figure 10. The GD's MIDF for the next three years.

\section{Discussion}

\subsection{Theoretical Implication}

First of all, industrial demand forecasting is a hot research topic. However, few people study the MIDF. Therefore, this paper selects the relevant factors and constructs the manufacturing demand forecasting index system. This provides an innovative perspective and enriches the literature of manufacturing demand forecasting. 
Secondly, the demand of the manufacturing industry is predicted by the deep learning model. By comparing the existing industry demand forecasting model, we find that the prediction results of deep learning are more accurate; this can provide a new perspective for the model selection of MIDF.

\subsection{Practical Implication}

The manufacturing industry is the fundamental support of high-quality economic development. Under the background of intelligent technology, the traditional manufacturing industry needs to adapt to the characteristics of a new round of scientific and technological revolution and industrial change. By integrating the production process with the new generation of information technology, the manufacturing industry can solve the technical bottleneck in its development.

In addition to technology affecting the demand of the manufacturing industry, FCI, government subsidies, service industry, and economy are also important factors to promote the manufacturing industry. Firstly, the GD's manufacturing industry should make full use of FCI, so that it can participate in the new international division system through its production and trade, as well as develop to the high end of the industrial chain. Secondly, the GD's government should reasonably subsidize the manufacturing industry, which can not only directly relieve the internal financial pressure of enterprises, but it can also indirectly provide convenience for manufacturing enterprises to realize external financing and encourage them to make more innovation investments. Third, the GD's government should promote the coordinated development of producer services and the manufacturing industry, and bring the service industry into every production link of the manufacturing industry. This can improve the production efficiency of the manufacturing industry and promote its high-quality development. Finally, the GD's government should grasp the law of economic operation and stimulate market vitality, thus facilitating the high-quality development of the manufacturing industry.

\section{Conclusions}

At present, there is a lack of in-depth research on the MIDF. Therefore, this study uses the manufacturing industry in GD as an example for demand forecasting. Based on the complex and diverse environment of manufacturing demand, this study establishes the index system for MIDF. In this context, the deep learning model is established for training, and five models are used for comparative study. The results show that: (1) the performance of deep learning is better than other methods; by comparing the results, the reliability of this study is verified. (2) Although the prediction based on the historical data of manufacturing demand alone is successful, the accuracy of the prediction results is significantly lower than when taking into account multiple factors. Finally, we put forward the development strategy of the manufacturing industry in GD. This is helpful for local governments to promote the sustainable development of the manufacturing industry.

The survey data come from one of China's provinces, whose characteristics may be quite different from those of others because the geographical location and economic development have an important impact on the manufacturing demand. Although this study is limited to a specific region, through further research this knowledge can be globally adopted and verified. For example, most countries and regions are faced with a mismatch between supply and demand in the manufacturing industry, such as overcapacity or insufficient capacity. Through accurate prediction of industrial demand, this will effectively avoid the waste of resources. Therefore, this case study is about, but is not limited to, GD. In terms of the scale of parallel development, it is also useful for Shandong and Jiangsu in China, Ruhr Industrial Zone in Germany, and Michigan in the United States.

Author Contributions: Methodology, Z.D. and Y.S.; software, Z.D. and C.W.; validation, Y.S. and T.W.; formal analysis, Z.D., Y.S., Y.Z., T.W., C.W. and S.F.; resources, T.W.; writing-original draft preparation, Z.D., Y.Z., C.W. and S.F.; writing-review and editing, Z.D., Y.S., Y.Z. and T.W.; supervision, Y.S. All authors have read and agreed to the published version of the manuscript. 
Funding: This research was funded by the National Natural Science Foundation Project under grant number 71571072, the National Social Science Foundation Project under grant number 18BGL236, the Guangdong Province Key Research and Development Project under grant number 2020B0101050001, and the Special Fund for Science and Technology Innovation Strategy of Guangdong Province under grant number pdjh2021b0405.

Institutional Review Board Statement: Not applicable.

Informed Consent Statement: Not applicable.

Data Availability Statement: The data in this paper are from the statistics bureau of Guangdong province. http:/ /stats.gd.gov.cn/ (accessed on 3 March 2021).

Acknowledgments: The authors thank the MDPI editor and anonymous reviewers for their numerous constructive comments and encouragement that have improved our paper greatly.

Conflicts of Interest: The authors declare no conflict of interest.

\section{References}

1. Dogan, A.; Birant, D. Machine learning and data mining in manufacturing. Expert Syst. Appl. 2021, 166, 114060. [CrossRef]

2. Wang, J.; Ma, Y.; Zhang, L.; Gao, R.X.; Wu, D. Deep Learning for Smart Manufacturing: Methods and Applications. J. Manuf. Syst. 2018, 48, 144-156. [CrossRef]

3. Anwar, S.; Sun, S. Foreign direct investment and export quality upgrading in China's manufacturing sector. Int. Rev. Econ. Financ. 2017, 54, 289-298. [CrossRef]

4. Qi, Y.; Yang, Y.; Yang, S.; Lyu, S. Does government funding promote or inhibit the financialization of manufacturing enterprises? Evidence from listed Chinese enterprises. N. Am. J. Econ. Financ. 2021, 58, 101463. [CrossRef]

5. Isaiah Zayone, T.; Henneberry, S.R.; Radmehr, R. Effects of Agricultural, Manufacturing, and Mineral Exports on Angola's Economic Growth. Energies 2020, 13, 1494. [CrossRef]

6. Kordalska, A.; Olczyk, M. Linkages between services and manufacturing as a new channel for GVC development: Evidence from CEE countries. Struct. Chang. Dyn. 2021, 58, 125-137. [CrossRef]

7. Lee, H.S.; Choi, Y. Environmental Performance Evaluation of the Korean Manufacturing Industry Based on Sequential DEA. Sustainability 2019, 11, 874. [CrossRef]

8. Maao Ua Ne, M.; Zouggar, S.; Krajai, G.; Zahboune, H. Modelling industry energy demand using multiple linear regression analysis based on consumed quantity of goods. Energy 2021, 225, 120270. [CrossRef]

9. Everingham, Y.; Sexton, J.; Skocaj, D.; Inman-Bamber, G. Accurate prediction of sugarcane yield using a random forest algorithm. Agron. Sustain. Dev. 2016, 36, 27. [CrossRef]

10. Yan, P.; Zhang, L.; Feng, Z.; Zhang, J. Research on Logistics Demand Forecast of Port Based on Combined Model. J. Phys. Conf. Ser. 2019, 1168, 032116. [CrossRef]

11. Yan, G. Forecasting of freight volume based on support vector regression optimized by genetic algorithm. In Proceedings of the 2nd IEEE International Conference on Computer Science and Information Technology, Beijing, China, 8-11 August 2009; pp. 550-553.

12. Güven, İ.; Şimşir, F. Demand forecasting with color parameter in retail apparel industry using artificial neural networks (ANN) and support vector machines (SVM) methods. Comput. Ind. Eng. 2020, 147, 106678. [CrossRef]

13. Meza, J.; Yepes, D.O.; Rodrigo-Ilarri, J.; Cassiraga, E. Predictive analysis of urban waste generation for the city of Bogotá, Colombia, through the implementation of decision trees-based machine learning, support vector machines and artificial neural networks. Heliyon 2019, 5, e02810. [CrossRef] [PubMed]

14. Shao, M.; Wang, X.; Bu, Z.; Chen, X.; Wang, Y. Prediction of energy consumption in hotel buildings via support vector machines. Sustain. Cities Soc. 2020, 57, 102128. [CrossRef]

15. Thomas Ng, S.; Skitmore, M.; Wong, K.F. Using genetic algorithms and linear regression analysis for private housing demand forecast. Build. Environ. 2008, 43, 1171-1184. [CrossRef]

16. Law, R. Back-propagation learning in improving the accuracy of neural network-based tourism demand forecasting. Tour. Manag. 2000, 21, 331-340. [CrossRef]

17. Enyiit, E.; Atici, U. Artificial neural network models for lot-sizing problem: A case study. Neural Comput. Appl. 2012, 22, 1039-1047.

18. Tanizaki, T.; Hoshino, T.; Shimmura, T.; Takenaka, T. Demand forecasting in restaurants using machine learning and statistical analysis. Procedia CIRP 2019, 79, 679-683. [CrossRef]

19. Liu, J.; Chang, H.; Forrest, J.Y.-L.; Yang, B. Influence of artificial intelligence on technological innovation: Evidence from the panel data of China's manufacturing sectors. Technol. Forecast. Soc. Chang. 2020, 158, 120142. [CrossRef]

20. Acemoglu, D.; Restrepo, P. The Race between Man and Machine: Implications of Technology for Growth, Factor Shares, and Employment. Am. Econ. Rev. 2018, 108, 1488-1542. [CrossRef]

21. Yu, Z.; Zhou, L.; Ma, Z.; El-Meligy, M.A. Trustworthiness Modeling and Analysis of Cyber-physical Manufacturing Systems. IEEE Access 2017, 5, 26076-26085. [CrossRef] 
22. Romero-Silva, R.; Hernández-López, G. Shop-floor scheduling as a competitive advantage: A study on the relevance of cyberphysical systems in different manufacturing contexts. Int. J. Prod. Econ. 2020, 224, 107555. [CrossRef]

23. Kuzior, A.; Lobanova, A. Tools of Information and Communication Technologies in Ecological Marketing under Conditions of Sustainable Development in Industrial Regions (Through Examples of Poland and Ukraine). J. Risk Financ. Manag. 2020, 13, 238. [CrossRef]

24. Tao, F.; Qi, Q. New IT Driven Service-Oriented Smart Manufacturing: Framework and Characteristics. IEEE Trans. Syst. Man Cybern. Syst. 2018, 49, 81-91. [CrossRef]

25. Leng, J.; Chen, Q.; Ning, M.; Jiang, P. Combining granular computing technique with deep learning for service planning under social manufacturing contexts. Knowl. Based Syst. 2017, 143, 295-306. [CrossRef]

26. Raluca, D.A.; Alecsandru, S.V. Main Determinants of Foreign Direct Investments in Romania-A Quantitative View of the Regional Characteristics Involved in the Investment Strategies of Foreign Companies. Procedia Soc. Behav. Sci. 2012, 58, 1193-1203. [CrossRef]

27. Fernandes, A.M.; Paunov, C. Foreign direct investment in services and manufacturing productivity: Evidence for Chile. J. Dev. Econ. 2012, 97, 305-321. [CrossRef]

28. Huang, Y.; Zhang, Y. How does outward foreign direct investment enhance firm productivity? A heterogeneous empirical analysis from Chinese manufacturing. China Econ. Rev. 2017, 44, 1-15. [CrossRef]

29. Liu, T.; Wang, J.; Zhu, Y.; Qu, Z. Linking economic performance and sustainable operations of China's manufacturing firms: What role does the government involvement play? Sustain. Cities Soc. 2021, 67, 102717. [CrossRef]

30. Zhao, L.; Chang, J.; Du, J. Dynamics analysis on competition between manufacturing and remanufacturing in context of government subsidies. Chaos Solitons Fractals 2019, 121, 119-128. [CrossRef]

31. Szirmai, A.; Verspagen, B. Manufacturing and economic growth in developing countries, 1950-2005. Struct. Chang. Econ. Dyn. 2015, 34, 46-59. [CrossRef]

32. Gabriel, L.F.; de Santana Ribeiro, L.C. Economic growth and manufacturing: An analysis using Panel VAR and intersectoral linkages. Struct. Chang. Econ. Dyn. 2019, 49, 43-61. [CrossRef]

33. Jiang, X.; Zhang, S. Visualizing the services embodied in global manufacturing exports. Phys. A Stat. Mech. Appl. 2021, 571, 125365. [CrossRef]

34. Liu, X.; Mattoo, A.; Wang, Z.; Wei, S.-J. Services development and comparative advantage in manufacturing. J. Dev. Econ. 2020, 144, 102438. [CrossRef]

35. Dou, Z.; Wu, B.; Sun, Y.; Wang, T. The Competitiveness of Manufacturing and Its Driving Factors: A Case Study of G20 Participating Countries. Sustainability 2021, 13, 1143. [CrossRef]

36. Dou, Z.; Sun, Y.; Wang, T.; Wan, H.; Fan, S. Exploring Regional Advanced Manufacturing and Its Driving Factors: A Case Study of the Guangdong-Hong Kong-Macao Greater Bay Area. Int. J. Environ. Res. Public Health 2021, 18, 5800. [CrossRef]

37. Xu, J.; Wang, B. Intellectual Capital, Financial Performance and Companies' Sustainable Growth: Evidence from the Korean Manufacturing Industry. Sustainability 2018, 10, 4651. [CrossRef]

38. Filippetti, A.; Frenz, M.; Ietto-Gillies, G. The impact of internationalization on innovation at countries' level: The role of absorptive capacity. Camb. J. Econ. 2017, 41, 413-439. [CrossRef]

39. Liu, X.; Zhang, X. Industrial agglomeration, technological innovation and carbon productivity: Evidence from China. Resour. Conserv. Recycl. 2021, 166, 105330. [CrossRef]

40. Guan, J.; Gao, X. Exploring the h-Index at Patent Level. JASIST 2009, 60, 35-40. [CrossRef]

41. Hall, L.A.; Bagchi-Sen, S. A study of R\&D, innovation, and business performance in the Canadian biotechnology industry. Technovation 2002, 22, 231-244.

42. Parthasarthy, R.; Hammond, J. Product innovation input and outcome: Moderating effects of the innovation process. J. Eng. Technol. Manag. 2002, 19, 75-91. [CrossRef]

43. Huang, L.; Dou, Z.; Hu, Y.; Huang, R. Online Sales Prediction: An Analysis with Dependency SCOR-Topic Sentiment Model. IEEE Access. 2019, 7, 79791-79797. [CrossRef]

44. Yu, X.; Liu, Y.; Huang, X.; An, A. Mining Online Reviews for Predicting Sales Performance: A Case Study in the Movie Domain. IEEE Trans. Knowl. Data Eng. 2012, 24, 720-734. [CrossRef]

45. $\mathrm{Hu}, \mathrm{Y}$.-C. Constructing grey prediction models using grey relational analysis and neural networks for magnesium material demand forecasting. Appl. Soft Comput. 2020, 93, 106398. [CrossRef]

46. Sathishkumar, V.E.; Cho, Y. Season wise bike sharing demand analysis using random forest algorithm. Comput. Intell. 2020. [CrossRef]

47. Jie, S.; Lee, W.J.; Liu, Y.; Yang, Y.; Peng, W. Forecasting Power Output of Photovoltaic Systems Based on Weather Classification and Support Vector Machines. IEEE Trans. Ind. Appl. 2015, 48, 1064-1069.

48. Fan, S.X.; Bin, W.U.; Business, S.O.; University, S.D. Prediction Analysis for Logistics Demand Based on Multiple Kernels. Ind. Eng. Manag. 2018, 23, 40-44.

49. Sadeghi, B. A BP-neural network predictor model for plastic injection molding process. J. Mater. Process. Technol. 2000, 103, 411-416. [CrossRef]

50. Yin, Z.; Jia, B.; Wu, S.; Dai, J.; Tang, D. Comprehensive Forecast of Urban Water-Energy Demand Based on a Neural Network Model. Water 2018, 10, 385. [CrossRef] 
51. Huang, L.; Dou, Z.; Hu, Y.; Huang, R. Textual Analysis for Online Reviews: A Polymerization Topic Sentiment Model. IEEE Access 2019, 7, 91940-91945. [CrossRef]

52. Sepp, H.; Jurgen, S. Long short-term memory. Neural Comput. 1997, 9, 1735-1780.

53. Zhao, J.; Hua, Q.; Zhao, J.; Jiang, D. Towards traffic matrix prediction with LSTM recurrent neural networks. Electron. Lett. 2018, 54, 566-568. [CrossRef]

54. Cortez, B.; Carrera, B.; Kim, Y.J.; Jung, J.Y. An architecture for emergency event prediction using LSTM recurrent neural networks. Expert Syst. Appl. 2018, 97, 315-324. [CrossRef]

55. Zhu, J.; Gong, Z.; Sun, Y.; Dou, Z. Chaotic neural network model for SMISs reliability prediction based on interdependent network SMISs reliability prediction by chaotic neural network. Qual. Reliab. Eng. Int. 2021, 37, 717-742. [CrossRef]

56. Dou, Z.; Hu, Y.; Cheng, P.; Huang, L.; Liang, J.; Xiao, H. Predicting Sales Performance Based on Polarity Sentiments of Online Reviews and Manifold Dynamics Method. In Proceedings of the 5th International Conference on Systems and Informatics (ICSAI), Nanjing, China, 10-12 November 2018; pp. 1138-1145.

57. David, F. Redressing grievances with the treatment of dimensionless quantities in SI. Measurement 2017, 109, 105-110. 